mi

马 w

$\geq=$

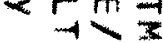

$x \rightarrow 1$

1210

ui is $=0$

(i) $=1+0$

$00<m$

$70 m-$

$n<<$

12

it $x$

$=0$

$+0-1=$

id $m m$

$4 \approx 0 \%$

in $D$

N $\quad \infty \frac{-1}{\infty}$

$N=\infty$

$+0$

is $\infty$

in

$\sum_{\infty}^{\infty}$

$\begin{array}{lll}0 & 5 & z \\ 0 & n & 0 \\ w & 0 & 1 \\ w & 0 & N \\ N & n & N \\ & & 0 \\ & & 0\end{array}$

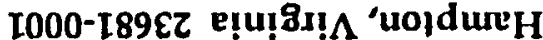

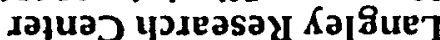
uo!jens!u!up ajeds pue so!jneuosov jeuo!jen

S66I Kienue [

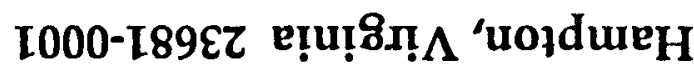

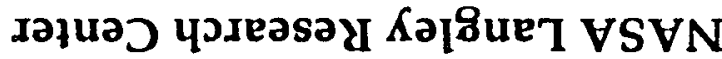
E]OH $5 \operatorname{sejn}^{\prime}$

SZLS-669EI XN 'unepsłod

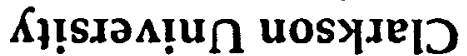

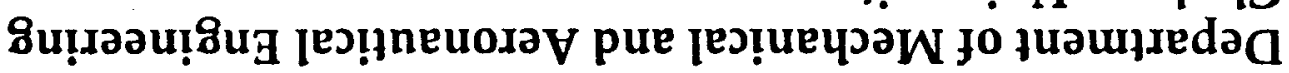
!peuy zxepoos

L000-L89عz e!u! 8 I! $\Lambda$ 'uo\}dure

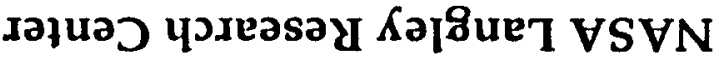

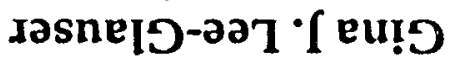

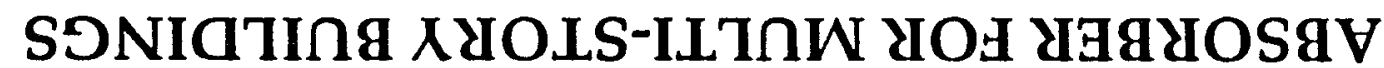

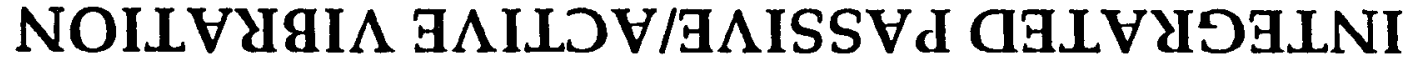

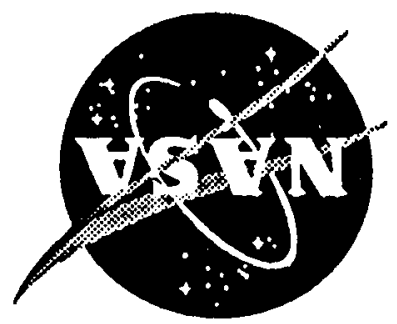

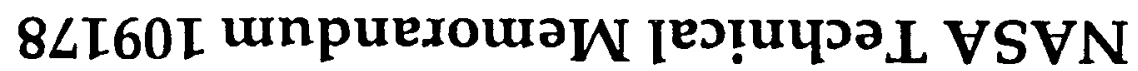

$6 C^{2}$

$2 t \varepsilon s t$

$|b \varepsilon-N|$ 


$$
\infty
$$




\title{
INTEGRATED PASSIVE/ACTIVE VIBRATION ABSORBER FOR MULTI-STORY BUILDINGS
}

\author{
Gina J. Lee-Glauser, * \\ NASA Langley Research Center \\ Hampton, Virginia 23681 \\ Goodarz Ahmadi, ${ }^{\dagger}$ \\ Department of Mechanical and Aeronautical Engineering \\ Clarkson University, Potsdam, NY 13699-5725 \\ Lucas G. Horta $\ddagger$ \\ NASA Langley Research Center \\ Hampton, Virginia 23681
}

\begin{abstract}
In this paper, a passive isolator, an active vibration absorber, and an integrated passive/active (hybrid) control are studied for their effectiveness in reducing structural vibration under seismic excitations. For the passive isolator, a laminated rubber bearing base isolator which has been studied and used extensively by researchers and seismic designers is studied. An active vibration absorber concept, which can provide guaranteed closed-loop stability with minimum knowledge of the controlled system, is used to reduce the passive isolator displacement and to suppress vibration. A three-story building model is used for the numerical simulation. The performance of an active vibration absorber and a hybrid vibration controller in reducing peak structural responses is compared with the passively isolated structural response under the N00W component of the El Centro 1940 and N90W component of the Mexico City earthquake excitation records. The results show that the integrated passive/active vibration control system is more effective in suppressing the peak structural acceleration for the El Centro 1940 earthquake than either the passive or active vibration absorber alone. The active vibration absorber, however, is the only system that suppresses the peak acceleration of the structure for the Mexico City 1985 earthquake.
\end{abstract}

*National Research Council Research Associate, Member AIAA.

†Professor

${ }^{\dagger}$ Assist. Branch Head, Structural Dynamics Branch, Member AIAA. 


\section{INTRODUCTION}

To alleviate detrimental seismic hazards, passive and active vibration control schemes have been introduced for protection of buildings and life lines. A historical review of passive structural isolation devices by Kelly [1,2] and recent studies by Su et al. [3] and Fan et al. [4] have shown that these devices have great potential to prevent earthquake damages to buildings, nuclear power plants, and sensitive subsystems within the structures. The most common passive isolation system is the Laminated Rubber Bearing (LRB) base isolator. A LRB isolator is quite flexible in the horizontal direction and rather stiff in the vertical direction. It is manufactured by alternating layers of rubber and steel with the rubber vulcanized to the steel plates. The horizontal flexibility of LRB isolator shifts the fundamental frequency of vibration away from the high energy frequency range of earthquake ground motion. The bearing is designed to resist wind forces with little or no deformation.

Active vibration control methodologies for civil structures have been explored extensively in recent years as reported by Soong [5], Meirovitch [6], and Reinhorn and Manolis [7]. Chawla et al. [8] used axial-force-rated actuators to suppress seismic vibration. For random disturbance cancellation of a multi-degree-of-freedom system, Nonami et al. [9] designed a feedback and feedforward controller using a model dependent active vibration absorber. They designed a feedback and feed-forward controller to control the first two modes of the structure. Their numerical and experimental results show significant vibration reduction under random disturbance forces. Unlike Nonami's active dynamic vibration absorber, Lee-Glauser et al. [10] designed a model independent active vibration absorber (AVA) controller to evaluate the closed-loop stability and its effectiveness in vibration suppression for a flexible space structure. The experimental results of Lee-Glauser et al. [10] show that the AVA controller significantly reduces the random disturbance into the flexible space structure model. Both Nonami et al. [9] and Lee-Glauser et al. [10] have experimentally demonstrated the validity of AVA controllers for vibration suppression in their applications. In this paper, the model independent AVA controller concept is used to design and evaluate the AVA's effectiveness in structural vibration reduction under seismic excitations.

The LRB base isolator has been shown $[1-4,11,12]$ to be highly effective in reducing the structural vibration under seismic excitation. This vibration reduction capability, however, is associated with a certain amount of base displacement. With a large passive element displacement, there are difficulties with the design and construction of appropriate connections for the infrastructures such as plumbing, electrical, and communication conduits. Therefore, developing an active control mechanism for reducing the base displacement to a manageable level is highly desirable. In addition, Su et al. [3] and Fan et al. [4] have shown that passive base isolation systems are ineffective for protection against earthquakes with considerable energy at low frequencies. In those cases the use of active and or hybrid systems may be recommended.

In this study, the effectiveness of an active vibration absorber and an integrated passive/active control in reducing structural vibration under seismic excitations are analyzed. The results are compared with that of the passive LRB system and the peak structural responses in absence of the control systems. The N00W component of El Centro 1940 and the N90W component of Mexico City 1985 earthquakes are used to excite a three story building model in the numerical simulation. The peak acceleration responses for various controllers are evaluated and the results are presented as response spectra curves. The special case where the active vibration absorber is tuned to the passive isolator natural frequency is studied in detail. 


\section{PROBLEM FORMULATION}

The governing equations of motion for a general multi-story shear frame structure with a passive vibration isolator are

$$
M \ddot{x}+C \dot{x}+K x=-M\left(\ddot{x}_{b}+\ddot{x}_{g}\right)\{1\}
$$

where $M, C$, and $K$ are mass, damping, and stiffness matrices, respectively, and $x$ is the vector containing the floor displacement relative to the base. As shown in Figure $1, x_{b}$ is the relative displacement between the base of the structure and the ground, $\ddot{x}_{g}$ is the horizontal ground acceleration, and $\{1\}$ is a column vector whose elements are all unity. For a fixed-base structure (without a passive isolator), $\ddot{x}_{b}=0$. In this study, a three-story building is the structural model. The mass of each floor, the base isolation device, the stiffness, and the damping matrices are all assumed to be identical. For this structural model, the damping matrix is proportional to the stiffness matrix. Numerical values for all matrices used are listed in Appendix A. A fundamental natural frequency of $3.33 \mathrm{~Hz}$ and a damping ratio of 0.02 are assumed for the structure. For peak acceleration response analyses, a range of fundamental natural frequencies of the building are used.

The equations of motion for passive and active vibration control systems are summarized in the following subsections.

\section{Passive Vibration Isolator}

For a laminated rubber bearing base isolator, the equation of motion of the passive system is given as,

$$
\ddot{x}_{b}+\frac{2 \zeta_{b} \omega_{b} \dot{x}_{b}+\omega_{b}^{2} x_{b}}{\alpha_{b}}-\frac{c_{1} \dot{x}_{1}+k_{1} x_{1}}{m_{b}}=-\ddot{x}_{g}
$$

The natural frequency of the laminated rubber bearing $\omega_{b}$, and its effective damping ratio $\zeta_{b}$ are defined as

$$
2 \zeta_{b} \omega_{b}=\frac{c_{b}}{m_{t}}, \quad \omega_{b}^{2}=\frac{k_{b}}{m_{t}}
$$

where $m_{t}$ is the total mass of the structure, and $c_{b}$ and $k_{b}$ are the damping and the horizontal stiffness of the bearing, respectively. The parameter $\alpha_{b}$ is the ratio of base mass to the total mass of the structure. i.e.,

$$
\alpha_{b}=\frac{m_{b}}{m_{t}}, \quad m_{t}=m_{b}+\sum_{i=1}^{3} m_{i}
$$

where $m_{i}$ is the $i$ th floor mass, and $m_{b}$ is the effective base mass of the structure.

In this study, a commonly suggested natural frequency of $0.5 \mathrm{~Hz}$ is used for the LRB base isolation. The effective damping ratio of the rubber varies between 0.05 at high strain to about 0.3 at low strain according to Derham [11] and Tajirian and Kelly [12]. Here, a typical effective damping ratio of 0.08 is used. 


\section{Active Vibration Absorber}

Consider an $\mathrm{n}$-mode structural dynamics model with only the acceleration measurement of the system masses. The governing equations are written as

$$
M \ddot{x}+D \dot{x}+K x=B u, \quad y=H_{a} \ddot{x},
$$

where $\mathrm{B}$ is a $n \times p$ actuator force distribution matrix for the $p \times 1$ control vector $u, y$ is the $m \times$ 1 measurement vector, and $H_{a}$ is the $m \times n$ acceleration influence matrix.

The second-order AVA controller, is governed by the system equations

$$
M_{c} \ddot{x}_{c}+D_{c} \dot{x}_{c}+K_{c} x_{c}=B_{c} u_{c}, \quad y_{c}=H_{a c} \ddot{x}_{c}
$$

where $x_{c}$ is an $n_{c} \times 1$ controller displacement vector, and $M_{c}, D_{c}$, and $K_{c}$ can be interpreted as the controller mass, damping, and stiffness matrices, respectively. $B_{c}$ is the $n_{c} \times m$ controller influence matrix for the $m \times 1$ input force vector $u_{c}$. Here, $y_{c}$ is a $p \times 1$ controller measurement vector, and $H_{a c}$ is the $p \times n_{c}$ acceleration influence matrix. The above controller equations for the AVA controller use fictitious mass, damping, and stiffness, therefore, they do not represent any physical system. The controller mass, damping, and stiffness matrices are, in general, symmetric and positive definite, so that the controller is asymptotically stable.

For the interconnected controller and structure with collocated sensors/actuators, the control equation is revised to include a direct acceleration feedback designed to form a model-independent controller which guarantees the closed-loop stability regardless of any perturbations, i.e.,

$$
u=y_{c}-G_{a} y=H_{a c} \ddot{x}_{c}-G_{a} H_{a} \ddot{x},
$$

where, $G_{a}$ is a gain matrix defined as

$$
G_{a}=H_{a c} M_{c}^{-1} B_{c} .
$$

Since the sensors/actuators are collocated,

$$
B=H_{a}^{T} \text { and } H_{a c}=B_{c}^{T} .
$$

Let, $B_{c}$ be defined as

$$
B_{c}=M_{c} \bar{B}_{c} \text { or } \quad \bar{B}_{c}=M_{c}^{-1} B_{c}
$$

then the closed-loop mass matrix becomes

$$
M_{t}=\left[\begin{array}{cc}
M+H_{a}^{T} \bar{B}_{c}^{T} M_{c} \bar{B}_{c} H_{a} & -H_{a}^{T} \bar{B}_{c}^{T} M_{c} \\
-M_{c} \bar{B}_{c} H_{a} & M_{c}
\end{array}\right]
$$

which is symmetric. To assure positive definiteness

$$
x_{t}^{T} M_{t} x_{t}>0,
$$


must be true for all real closed-loop displacement vectors $x_{t}$ except the null vector. Substituting $M_{t}$ into Eq. (12) yields

$$
x_{t}^{T} M_{t} x_{t}=x^{T} M x+\left(M_{c}^{-1} B_{c} H_{a} x-x_{c}\right) M_{c}\left(M_{c}^{-1} B_{c} H_{a} x-x_{c}\right)
$$

which is positive definite as long as $M$ and $M_{c}$ are positive definite. With the collocated sen-

sors/actuators, it is assumed that $\bar{B}_{c}=H_{a}=1$. This AVA design has been used and verified experimentally and numerically by Lee-Glauser et al. [10].

In this study, the second-order controller is assumed to be attached to the third floor as shown in Figure 1. The AVA control law is

$$
u=-m_{c}\left(\ddot{x_{3}}+\ddot{x}_{c}\right)
$$

The $x_{c}$ is computed from

$$
m_{c} \ddot{x}_{c}+d_{c} \dot{x}_{c}+k_{c} x_{c}=-m_{c} \ddot{x_{3}}
$$

where $m_{c}, d_{c}$, and $k_{c}$ are the controller parameters. The optimum AVA controller parameters are obtained by using the frequency matching method which was described in [10]. Here, the active vibration absorber is designed to enhance the passive isolator that requires less than $0.3 \mathrm{~g}$ of input force. For seismic application, the actuator mass is negligible in comparison to the structure model. Therefore, the importance of the actuator dynamics as reported by Inman [13] is not included in the numerical simulation.

\section{NUMERICAL STUDIES}

In this section, performance of passive, active, and hybrid vibration control systems in protecting the structure subjected to the N00W component of El Centro 1940 and N90W component of Mexico City 1985 earthquake records are studied. The normal modes expansion technique is used to analyze the dynamic response of the structure.

\section{El Centro 1940 Earthquake}

The N00W component of El Centro 1940 earthquake which has the features of many common earthquakes is used in this section as the ground excitation. Figure 2 shows sample time histories of the absolute third floor lateral accelerations for each of the vibration controllers and the uncontrolled structure with a natural frequency of $3.3 \mathrm{~Hz}$. It is observed that all three controllers are highly effective in reducing the peak absolute acceleration. However, the vibration reduction of about $75 \%$ to $85 \%$ is noticed with the passive and the hybrid systems. The resulting response for the LRB isolator is also in good agreement with that of Fan et al. [4]. Although, the AVA controller is tuned to the passive isolator using only small input force, this figure shows that it still is an effective vibration suppression alone.

Figure 3 shows the sample absolute acceleration time histories at various floors for different vibration control systems. The time history of the ground motion in Figure 3a is that of the N00W component of El Centro 1940 earthquake. It is observed that the uncontrolled 3-story building model used is behaving like a shear beam structure. That is, the absolute acceleration amplitude increases as the floor level increases. The peak acceleration amplification is about $72 \%$ 
from first to third floor. With the active AVA controller as shown in Figure 3b, the absolute acceleration level at all floors is reduced in comparison to Figure 3a, however, the amplification of the transmitted acceleration at higher floors is noticeable. A structure with passive and hybrid controllers shows significant acceleration reduction at all floor levels as shown in Figures 3c and 3d. Furthermore, the passive and hybrid systems filter the high frequency contents of the ground acceleration. Figures $3 \mathrm{c}$ and $3 \mathrm{~d}$ also show that the acceleration time histories of different floors are roughly the same. This implies that when passive and/or hybrid control systems are used, the super-structure vibrates more like a rigid body and does not amplify the ground excitation.

Fourier decompositions of the acceleration responses at each floor for various vibration control systems are shown in Figure 4. This figure shows the frequency content of the acceleration at different floors for structure with and without vibration control devices. The Fourier spectrum of the ground shown in Figure 4a is that of the accelerogram of the N00W component of the El Centro 1940 earthquake. It is observed that the ground acceleration has a broad spectrum in the frequency range of 1 to $5 \mathrm{~Hz}$. During an earthquake, the unprotected building filters the broad-band excitation into narrow-band vibration at its fundamental frequency. Figure $4 \mathrm{a}$ shows the sharpening of the spectrum near the natural frequency of $3.3 \mathrm{~Hz}$ for the building model used. That is, the peak spectrum amplitude at $3.3 \mathrm{~Hz}$ increases sharply as the acceleration propagates to the higher floors. The Fourier spectra of the structure with the AVA controller is shown in Figure 4b. The spectra contains approximately the same frequency components as those of the ground acceleration but with reduced amplitudes. That is, the AVA controller does not filter out the broad-band excitation, but does significantly reduce the peak resonance observed in the uncontrolled case. Figure 4c shows the floor acceleration Fourier spectra for a structure with an LRB isolation system. The rigid body motion of the super-structure is observed to be identical responses at different floors. The dominant frequency observed in this figure is about $0.5 \mathrm{~Hz}$ which corresponds to the LRB system natural frequency. That is, the base isolation filters out the high frequency energy content of the earthquake acceleration, but amplifies the energy at its natural frequency. Since the ground excitation has little energy in this range, the peak acceleration of the structure remains quite low. The Fourier spectra of the hybrid controller are shown in Figure 4d. While the general trend of the spectra is similar to that of Figure 4c, the sharp peaks observed in the passive controller responses have been significantly reduced by use of the hybrid AVA controller in conjunction with the LRB isolator. Here, the AVA controller is tuned at the fundamental frequency of the passive system.

The peak third floor absolute acceleration responses shown in Figure 5 are calculated for the building fundamental mode frequency of 1 to $10 \mathrm{~Hz}$ for various vibration control systems. The uncontrolled response spectra is also shown in this figure for reference. This figure clearly shows that the LRB and the hybrid systems are highly effective in reducing the peak acceleration responses, with the hybrid system reduced the most throughout the frequency range examined. The active vibration absorber system is not as effective as the passive isolator and the hybrid system. Once again, this is due to the power constraint on the active controller.

Figure 6 depicts the peak base displacements of the passive and hybrid systems for the fundamental mode frequencies of 1 to $10 \mathrm{~Hz}$. It is observed that the hybrid system leads to base displacement that is $20 \%$ less than that for the passive system. This base movement reduction can be a significant factor for protection of the infrastructure (such as, plumbing, electrical and communication conduits) connections at the building foundation. The results show that the passive system alone can provide protection for the structure against earthquake. However the accom- 
panying large base displacement requires special connection devices for the lifelines; whereas, the hybrid controller can protect the structure even more effectively while reducing the peak base displacement.

\section{Mexico City 1985 Earthquake}

In this section the structural responses to the N90W component of the Mexico City 1985 earthquake is studied. Figure 7 shows sample time histories of the absolute accelerations at the third floor for various controllers. It is observed that for this long period earthquake, the passive and hybrid controllers actually amplifies the structural vibration by an order of magnitude. However, the active controller reduces the peak absolute acceleration by about $40 \%$

The sample absolute acceleration time histories and their frequency content at various floors for different vibration control systems are shown in Figures 8 and 9. The N90W component of the Mexico City 1985 earthquake ground acceleration and its frequency decomposition are shown in Figures 8a and 9a. It is observed that the uncontrolled structure performs reasonable well in the Mexico City earthquake excitation. This is because the ground acceleration of the Mexico City earthquake was roughly a sinusoidal excitation with a frequency of $0.5 \mathrm{~Hz}$ and the structure was relatively stiff with a fundamental natural frequency of $3.33 \mathrm{~Hz}$. The structure with passive and hybrid LRB systems, however, amplifies the ground acceleration. The reason for this is that the LRB shifts the fundamental period of the system to about $0.5 \mathrm{~Hz}$. Figure 9 shows that the entire energy of the ground excitation for the Mexico City earthquake is concentrated near this frequency. The amplitude of the structural vibrations then increases significantly due to resonance. The AVA controller appears to be the only protective system that is effective in reducing the floor accelerations of the structure for this long period excitation. Figure $9 \mathrm{~b}$ shows that the sharp spectral peak at $0.5 \mathrm{~Hz}$ is totally eliminated with the use of the AVA controller. Figures 8 and 9 also show that the uncontrolled and active controlled structure amplify the floor acceleration with height. The passive and hybrid controlled structures behave like a rigid body with approximately fixed floor acceleration time histories. However, the vibration amplitude is quite high for the LBR system.

Figure 10 shows the peak third floor acceleration responses for the building fundamental mode in the frequency range of 1 to $10 \mathrm{~Hz}$ for various vibration control devices. For the uncontrolled case, it is observed that the response contains a sharp peak at a low frequency of about $1.4 \mathrm{~Hz}$. This figure also shows that the passive and hybrid controllers are totally ineffective for this long period earthquake. The active AVA controller, however, provides effective vibration suppression for the Mexico City 1985 earthquake.

Figure 11 displays the peak base displacement of the LRB and the Hybrid systems for various fundamental mode frequencies. It is observed that the base displacements for the LRB system is as large as $8 \mathrm{~cm}$. The use the hybrid system reduces the peak displacement to about $4 \mathrm{~cm}$.

\section{CONCLUSIONS}

The performance of a passive (LRB) isolator, active vibration absorber, and an integrated passive and active control (hybrid) systems in reducing structural vibration under seismic excitations was evaluated. The El Centro 1940 and long period Mexico City 1985 earthquake accelerograms were used as base excitations. Based on the presented results, the following conclusions may be drawn: 
1. The passive isolator, the integrated passive/active (hybrid) system, and the active AVA controller could be designed to be highly effective in suppressing structure vibrations. The degree of effectiveness of the systems depends on the type of earthquake, i.e. its expected frequency content.

2. For earthquakes with little energy over long periods (such as the El Centro 1940 earthquake), the passive and hybrid controllers are highly effective in reducing the transmitted acceleration.

3. For long period earthquakes (such as the Mexico City 1985 earthquake), the active AVA controller is the most effective in reducing the structural vibration. For earthquakes with considerable energy at low frequencies, the passive and hybrid controllers have an adverse effect and amplify the structural vibration.

4. The structure with a passive and/or hybrid control systems vibrates roughly in its rigid body mode. The uncontrolled structure and the one with an active AVA systems behaves as a shear beam and amplifies the transmitted acceleration along its floor.

5. The hybrid system reduces the sharp resonant peak at the fundamental frequency of the passive isolator.

6. The integrated passive/active (hybrid) vibration controller reduces the base isolation displacement from the passive isolator displacement.

The results of this study show that knowledge of the frequency content of the expected earthquake is necessary for the selection of the proper choice of a vibration control device. For earthquakes in cities on bedrock, the passive and/or the integrated passive/active controller is most effective in protecting structures. For cities with soft soil, the AVA active vibration controller is most appropriate.

\section{ACKNOWLEDGMENT}

This work is supported by the National Research Council at NASA Langley Research Center Grant 44.50.38.03.

\section{REFERENCES}

1. Kelly, J. M., "Aseismic Base Isolation: Review and Bibliography," Soil Dyn. Earthquake Engineering, Vol. 5, pp. 202-216, 1986.

2. Kelly, J. M., "Aseismic Base Isolation," Shock and Vibration Digest, Vol. 14, pp. 17-25, 1982.

3. Su, L., Ahmadi, G., and Tadjbaklısh, I. G., "A Comparative Study of Performances of Various Base Isolation Systems", Earthquake Engineering and Structural Dynamics, Vol. 18, pp. 11-32, 1989.

4. Fan, F. G., Ahmadi, G., Mostaghel, N., and Tadjbakhsh, I. G., "Performance Analysis of Seismic Base Isolation Systems for a Multi-Story Building", Soil Dynamics and Earthquake Engineering, Vol. 10, pp. 152-171, 1991. 
5. Soong, T. T., "Active Structural Control: Theory and Practice", Longman, London, and Wiley, New York 1990.

6. Meirovitch, L., "Dynamics and Control of Structure", Wiley-Interscience, New York 1990.

7. Reinhorn, A. M. and Manolis, G. D., "Recent Advances in Structural Control," Shock and Vibration Digest, Vol. 21, No. 1, pp. 3-8, 1989.

8. Chawla, V., Sener, M., Utku, S., and Wada, B. K., "Seismic Vibration Suppression by the Axial-Force-Rated Actuators", AIAA paper 94-1748-CP, AIAA/ASME/ASCE/AHS 35th Structures, Structural Dynamics and Materials Conf., Adaptive Structures Forum, Hilton Head Island, SC. April 21-22, pp. 143-150, 1994.

9. Nonami, K., Nishimura, H., and Cui, W., "Disturbance Cancellation Control for Vibration of Multi-Degree-of-Freedom Systems", JSME International Journal, Vol. 37, No. 1, pp. 86-93, 1994.

10. Lee-Glauser, G., Juang, J.-N., and Sulla, J.L., "Optimal Active Vibration Absorber: Design and Experimental Results", AIAA paper 93-1661, AIAA/ASME/ASCE/AHS 34th Structures, Structural Dynamics and Materials Conf., La Jolla, CA. April 19-21, pp. 3146-315, 1993. J. of Vibration and Acoustics (in press).

11. Derham, C. J., "Nonlinear Natural Rubber Bearings for Seismic Isolation", ATC-17 Seminar on Base Isolation and Passive Energy Dissipation, California, March, 1986.

12. Tajirian, F. F. and Kelly, J. M., "Seismic and Shock Isolation System for Modular Power Plants", The 1987 Pressure Vessels and Piping Conference, California, 1987.

13. Inman, D. J., "Control/Structure Interaction: Effects of Actuator Dynamics", AIAA-901223-CP, AIAA Dynamics Specialists Conf., Long Beach, CA. April 5-6, pp. 311-321, 1990.

\section{APPENDIX A}

In this appendix, structural parameters and their corresponding modal parameters used in this study are listed below. A three-story building without a passive isolation system parameters are given below:

$$
M=m\left[\begin{array}{lll}
1 & 0 & 0 \\
0 & 1 & 0 \\
0 & 0 & 1
\end{array}\right], \quad C=c\left[\begin{array}{rrr}
2 & -1 & 0 \\
-1 & 2 & -1 \\
0 & -1 & 1
\end{array}\right], \quad K=k\left[\begin{array}{rrr}
2 & -1 & 0 \\
-1 & 2 & -1 \\
0 & -1 & 1
\end{array}\right]
$$

The corresponding eigenvector is given by,

$$
\phi=\left[\begin{array}{rrr}
0.3280 & -0.7370 & 0.5910 \\
0.5910 & -0.3280 & -0.7370 \\
0.7370 & 0.5910 & 0.3280
\end{array}\right]
$$

and the equation of motion in terms of modal coordinates is

$$
\ddot{q}+\frac{c}{m}\left[\begin{array}{rrr}
.198 & 0 & 0 \\
0 & 1.555 & 0 \\
0 & 0 & 3.247
\end{array}\right] \dot{q}+\frac{k}{m}\left[\begin{array}{rrr}
.198 & 0 & 0 \\
0 & 1.555 & 0 \\
0 & 0 & 3.247
\end{array}\right] q=\left[\begin{array}{r}
-1.656 \\
0.474 \\
-0.182
\end{array}\right]\left(\ddot{x}_{b}+\ddot{x}_{g}\right)(A
$$




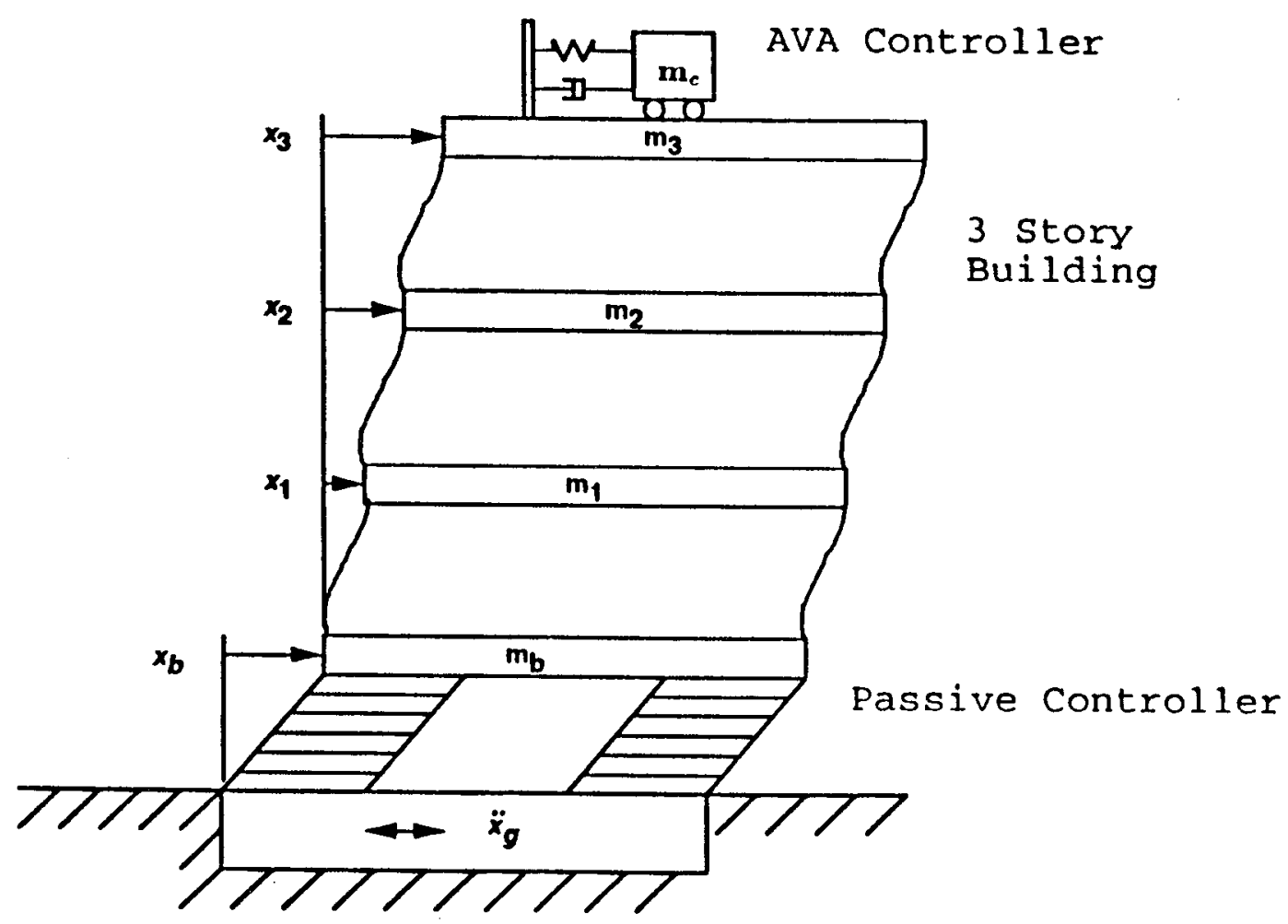

Figure 1: Schematic diagram of three-story building with passive and active controllers. 


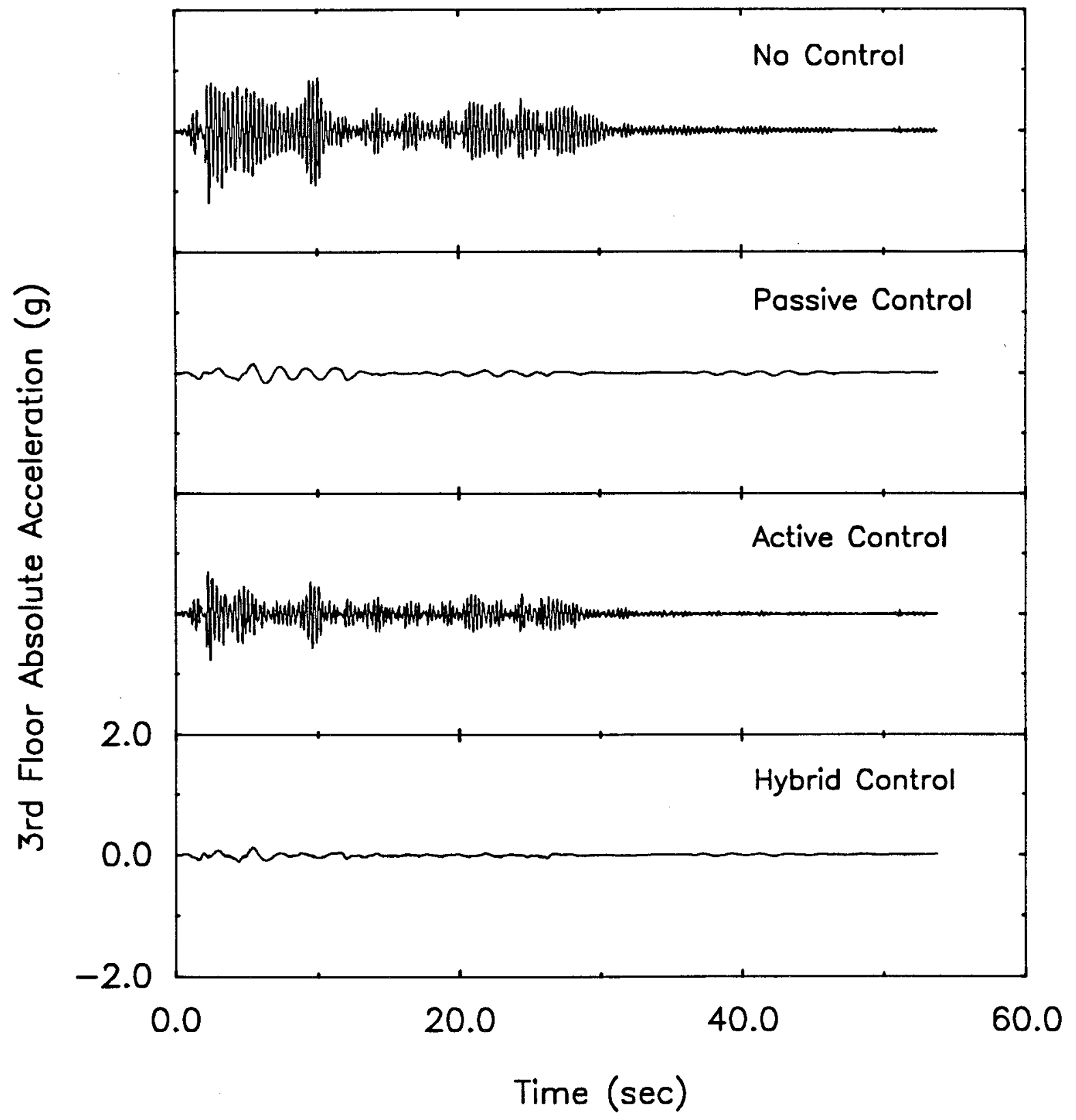

Figure 2: Sample time histories of the 3rd floor absolute accelerations for various vibration controllers and unprotected case for El Centro 1940 earthquake. 

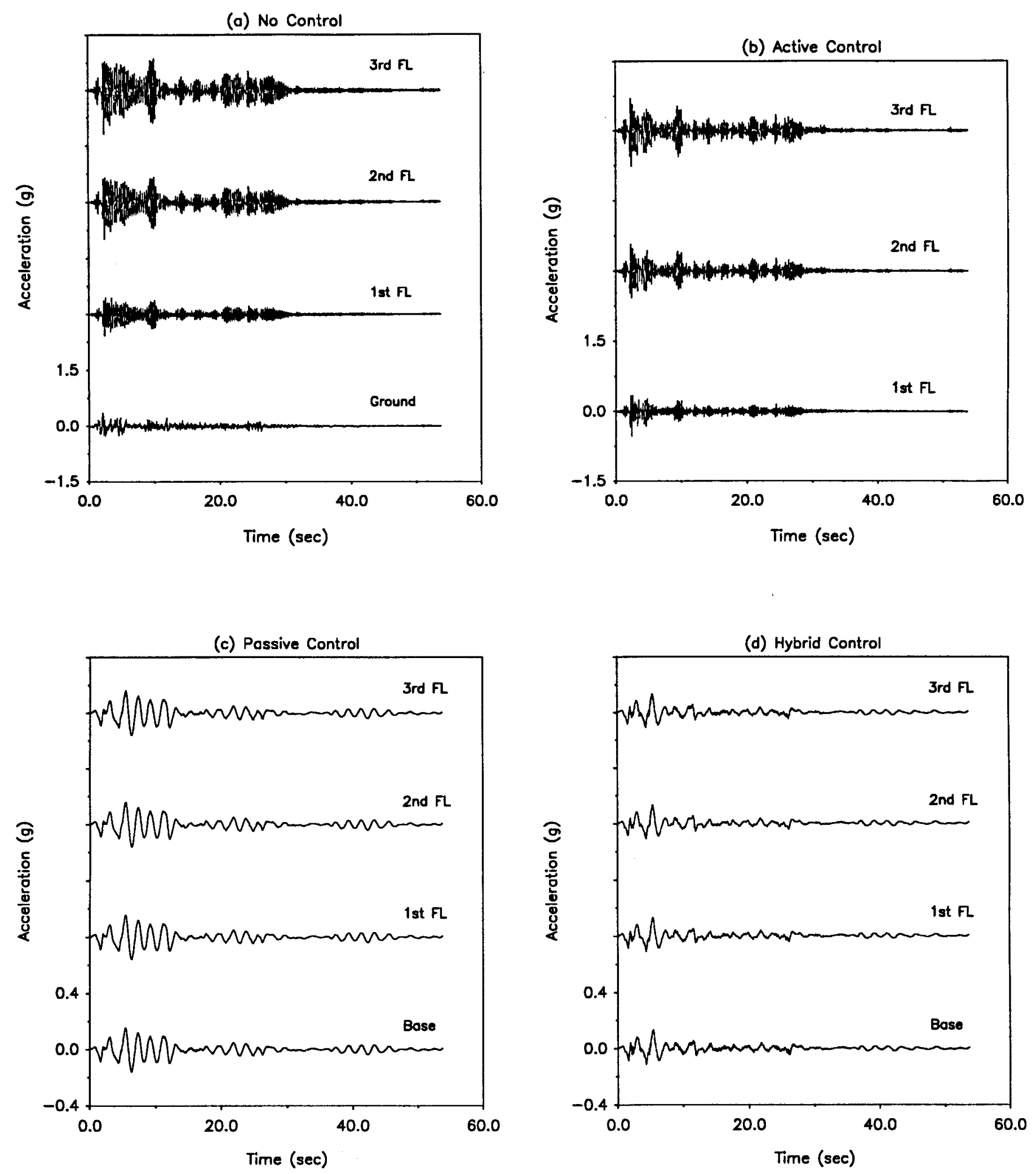

Figure 3: Absolute acceleration responses at various floors for different vibration control systems for El Centro 1940 earthquake. 
(o) No Control

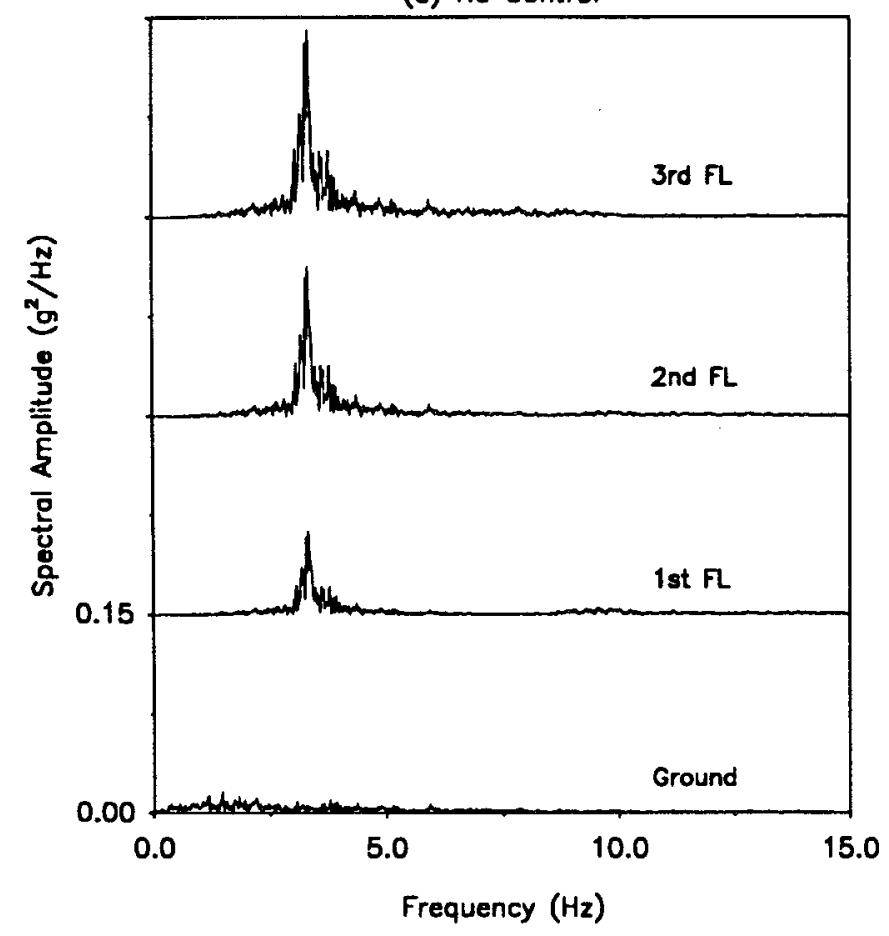

(o) No Control

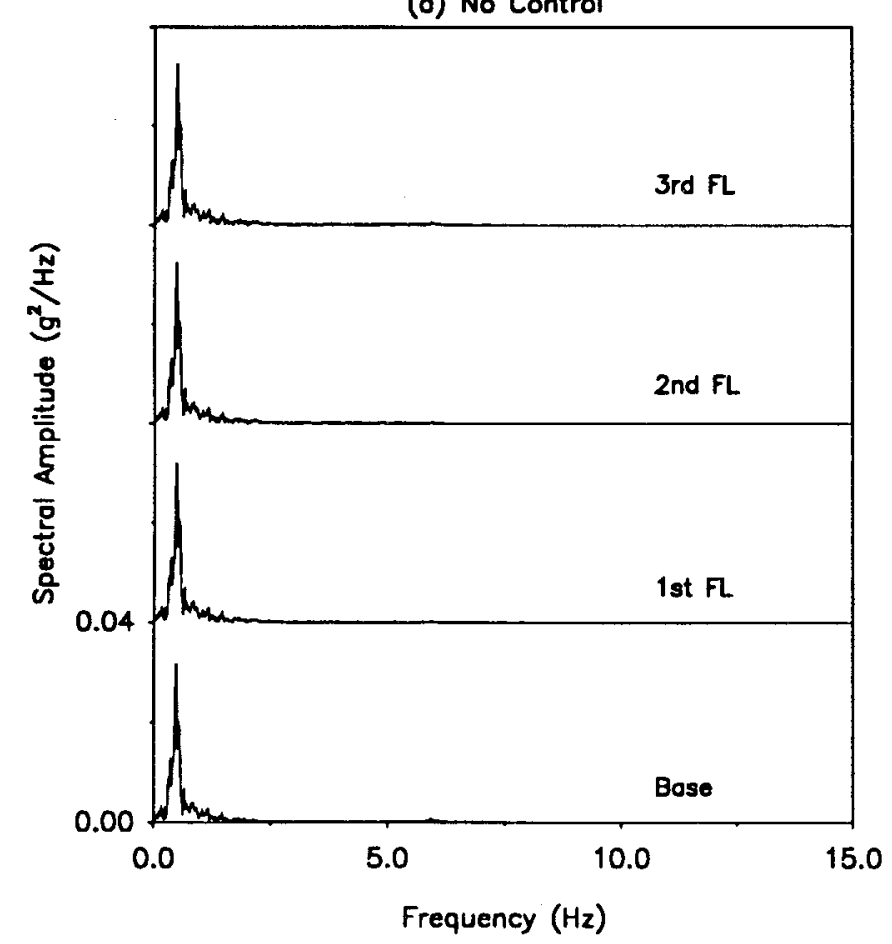

(b) Active Control

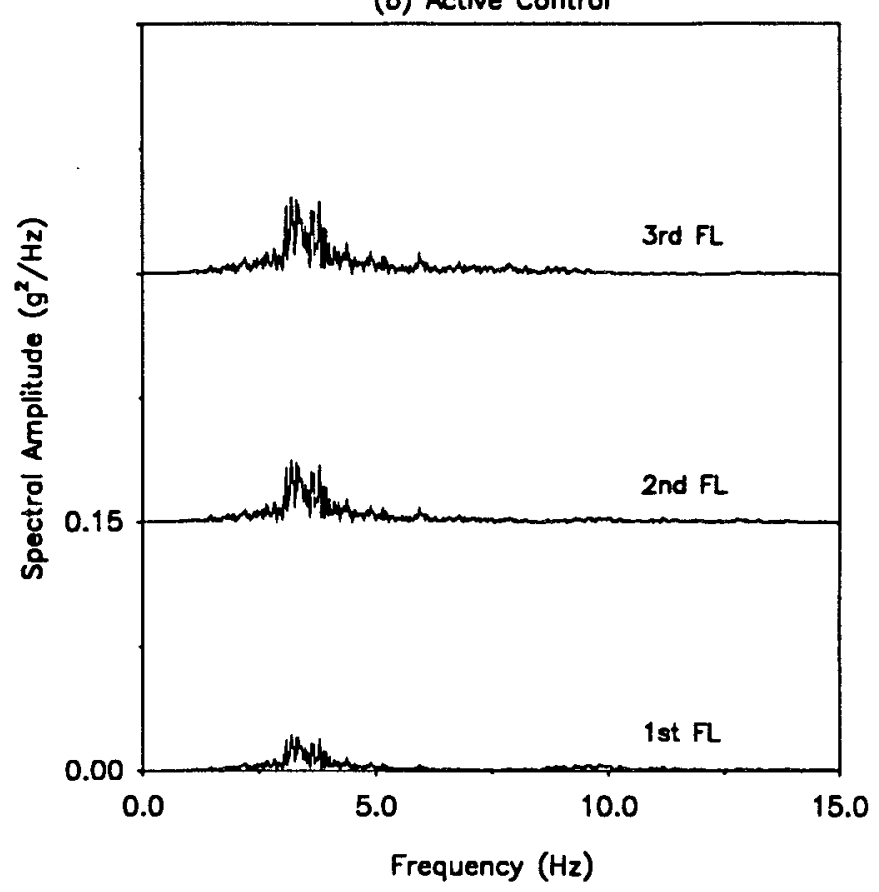

(d) Hybrid Control

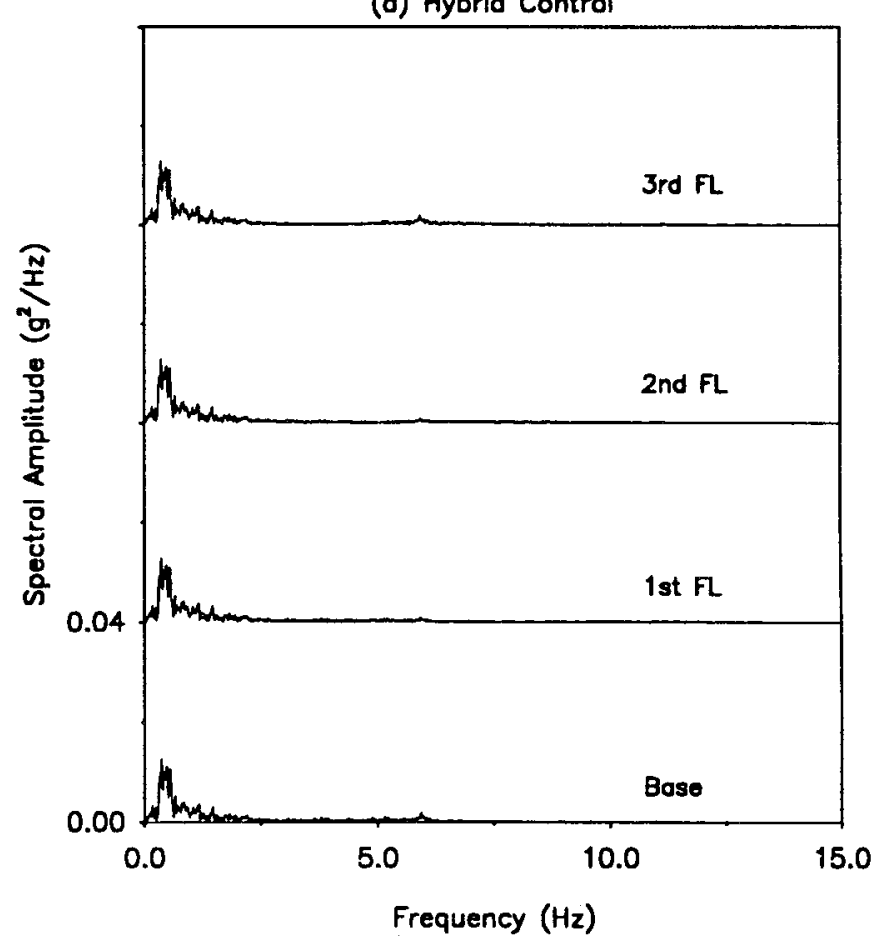

Figure 4: Fourier decompositions of acceleration responses at various floors for different vibration control systems for El Centro 1940 earthquake. 


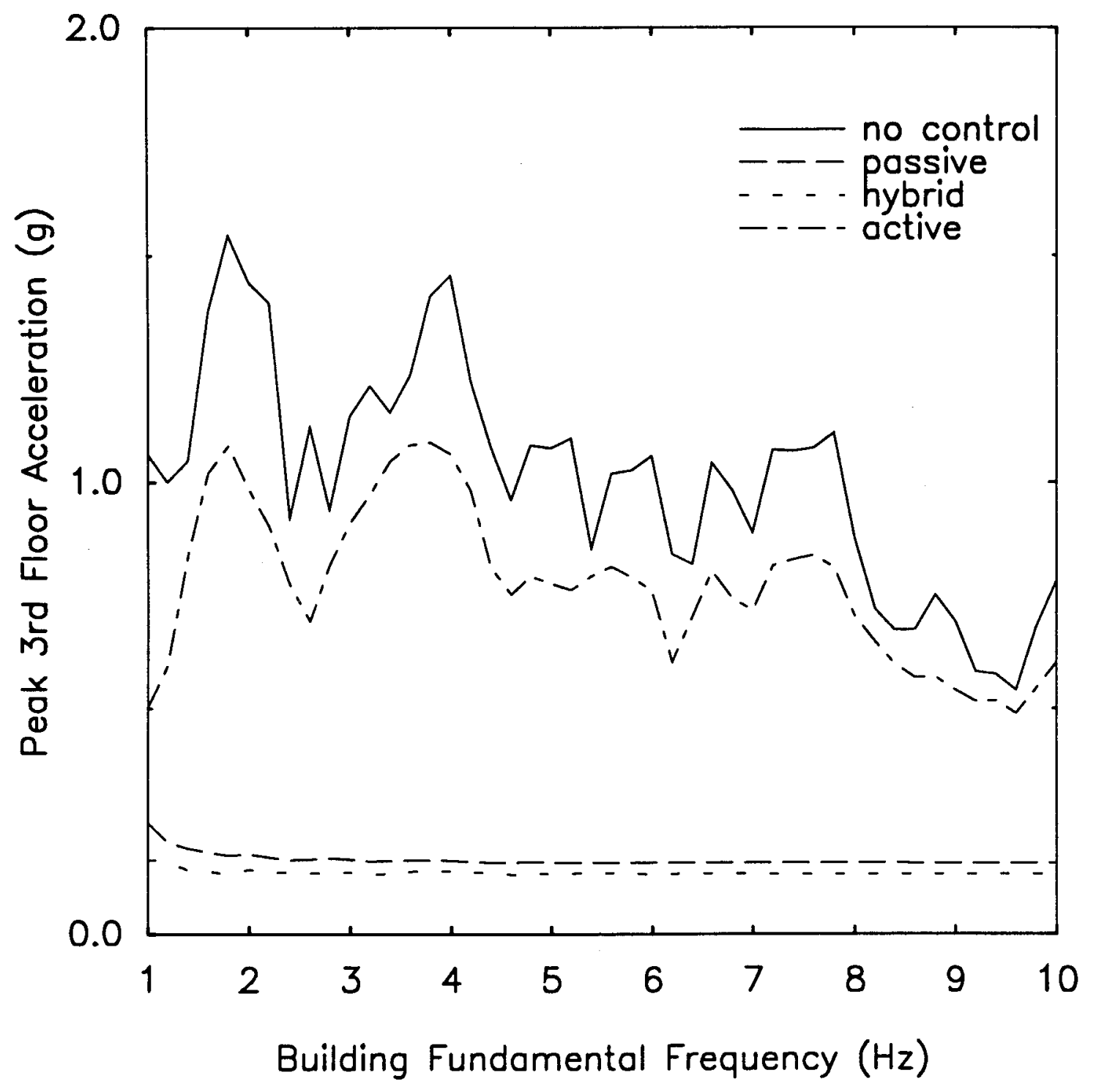

Figure 5: Peak 3rd floor acceleration responses for various vibration controllers for El Centro 1940 earthquake. 


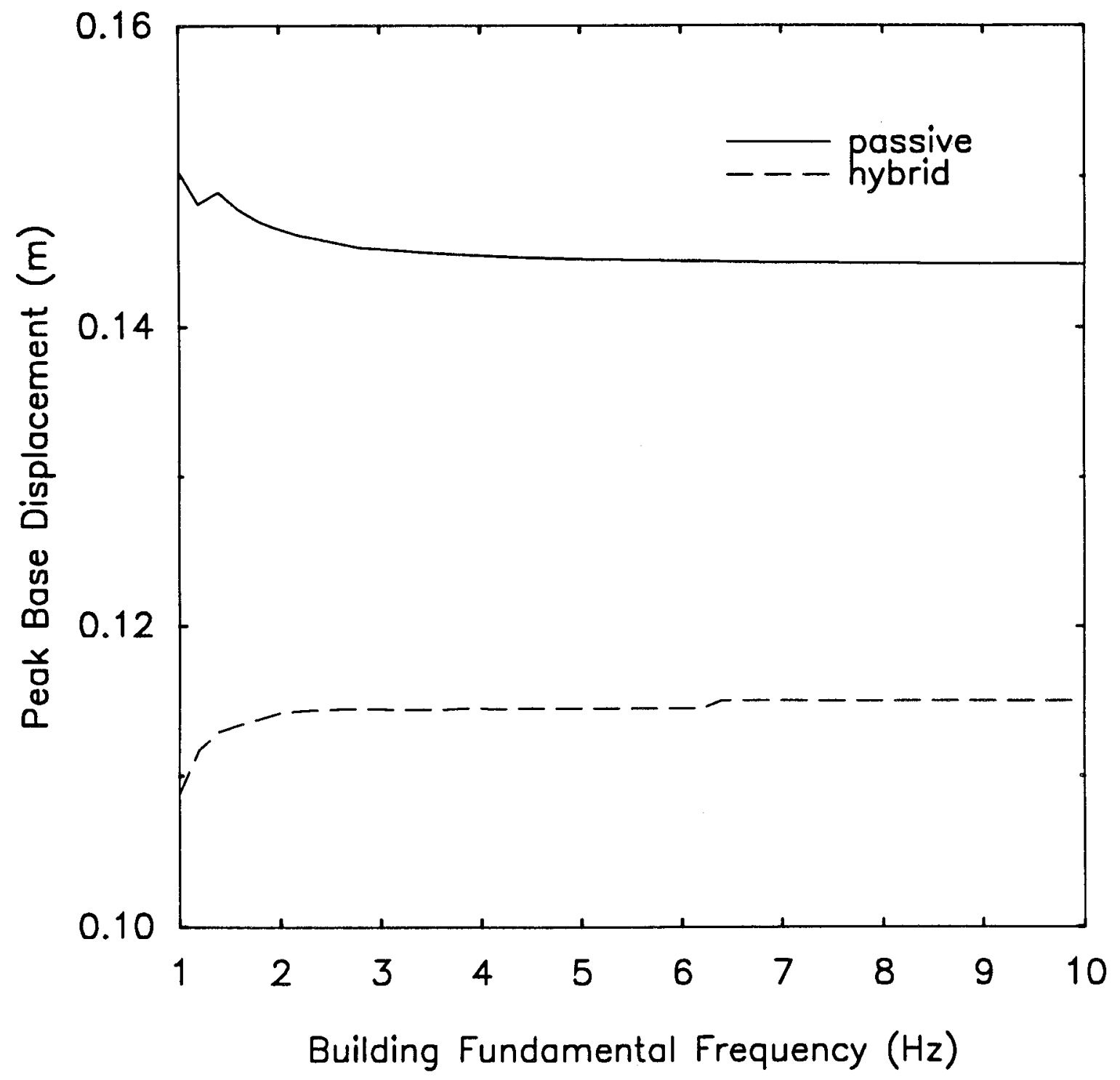

Figure 6: Peak base displacement responses for the LRB and hybrid systems for El Centro 1940 earthquake. 


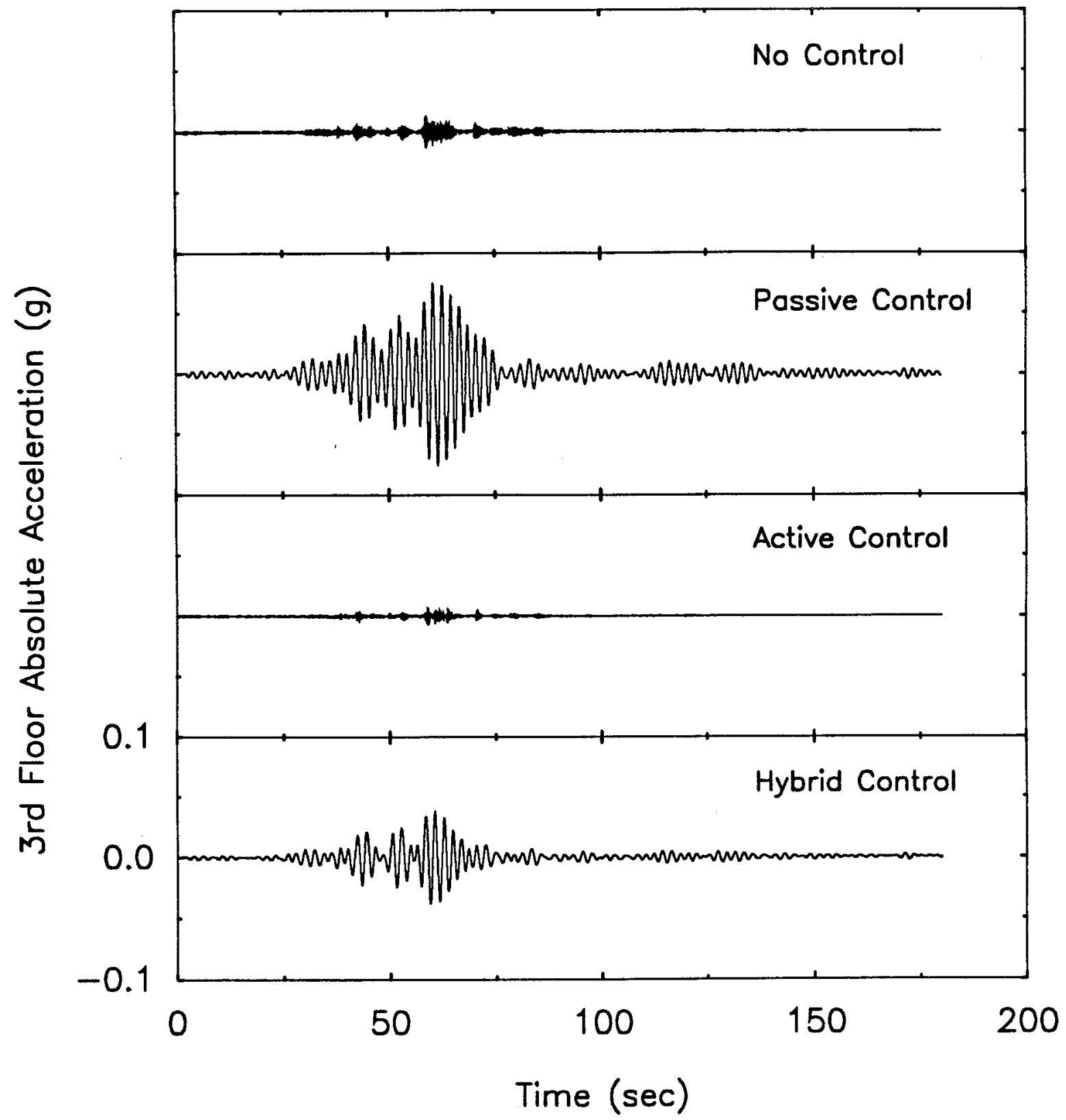

Figure 7: Sample time histories of the 3rd floor absolute accelerations for various vibration controllers and unprotected case for Mexico City 1985 earthquake. 

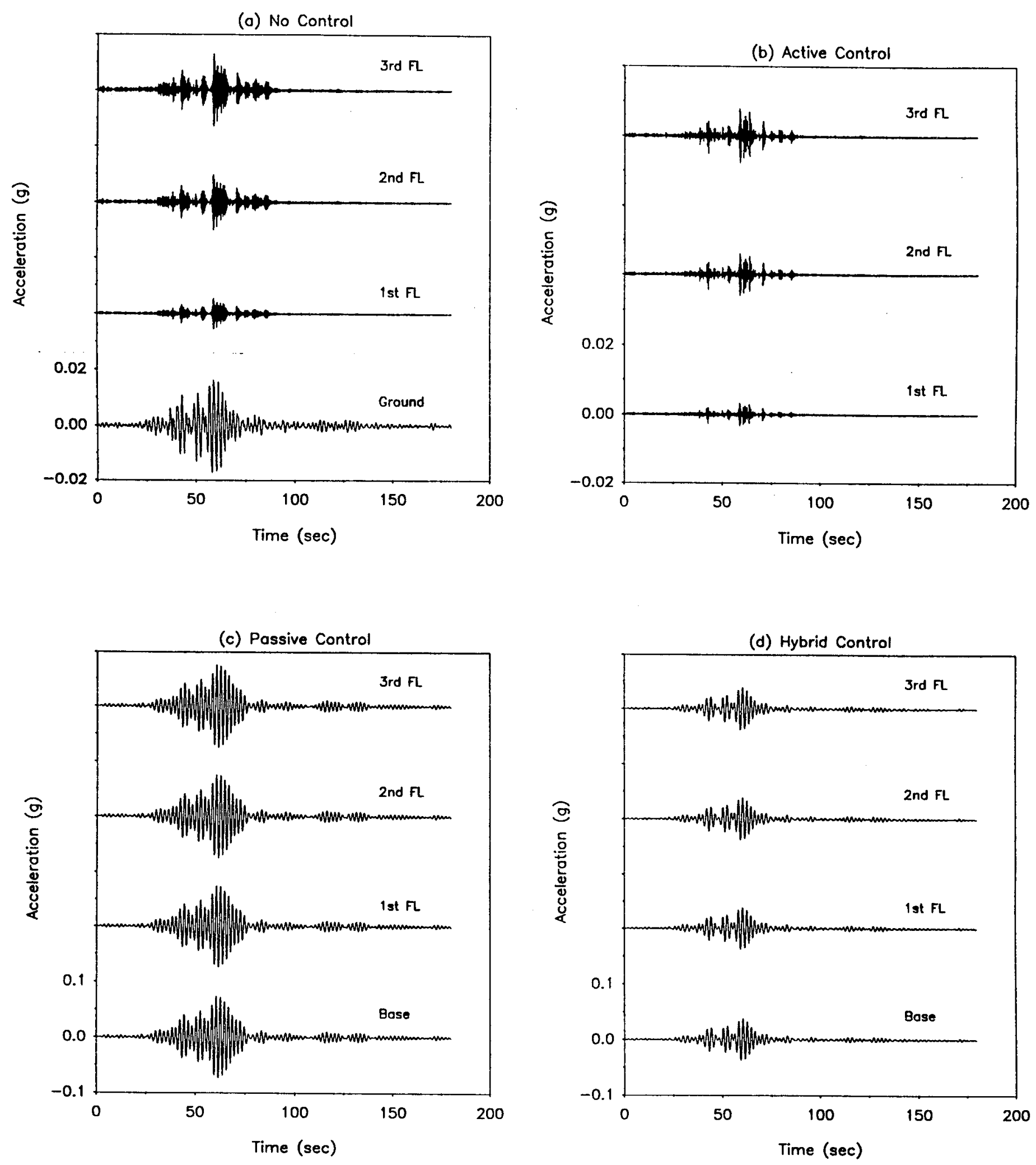

Figure 8: Absolute acceleration responses at various floors for different vibration control systems for Mexico City 1985 earthquake. 
(o) No Control

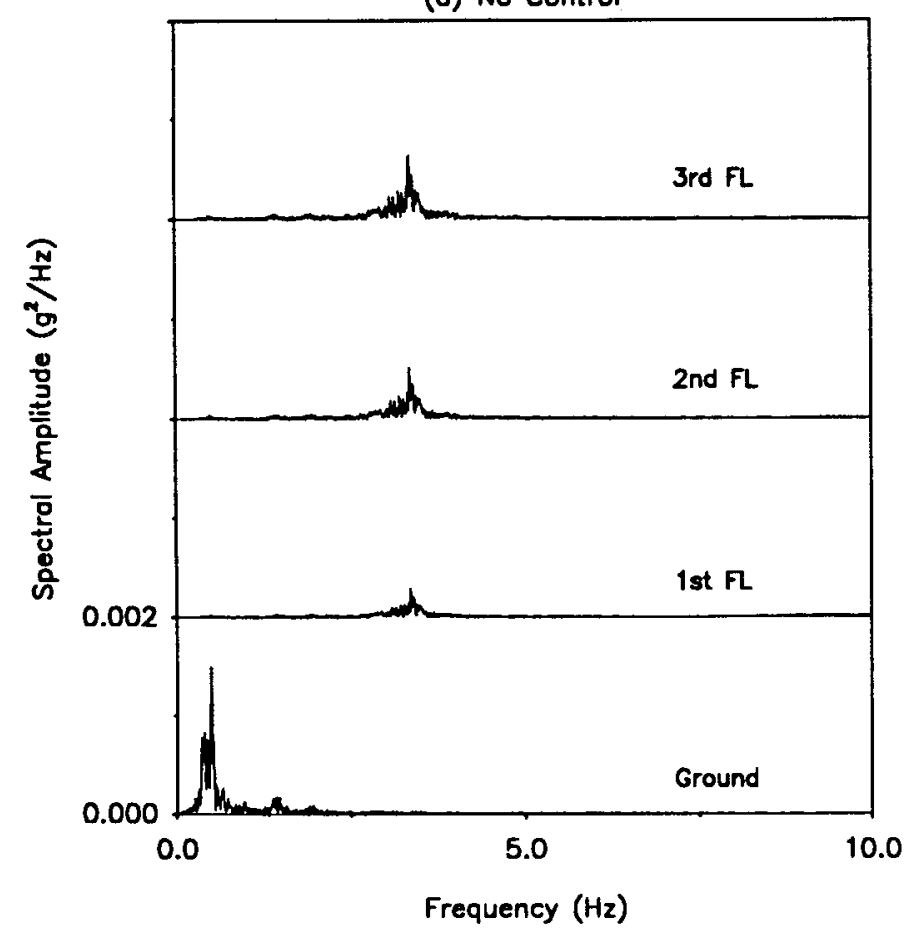

(c) Possive Control

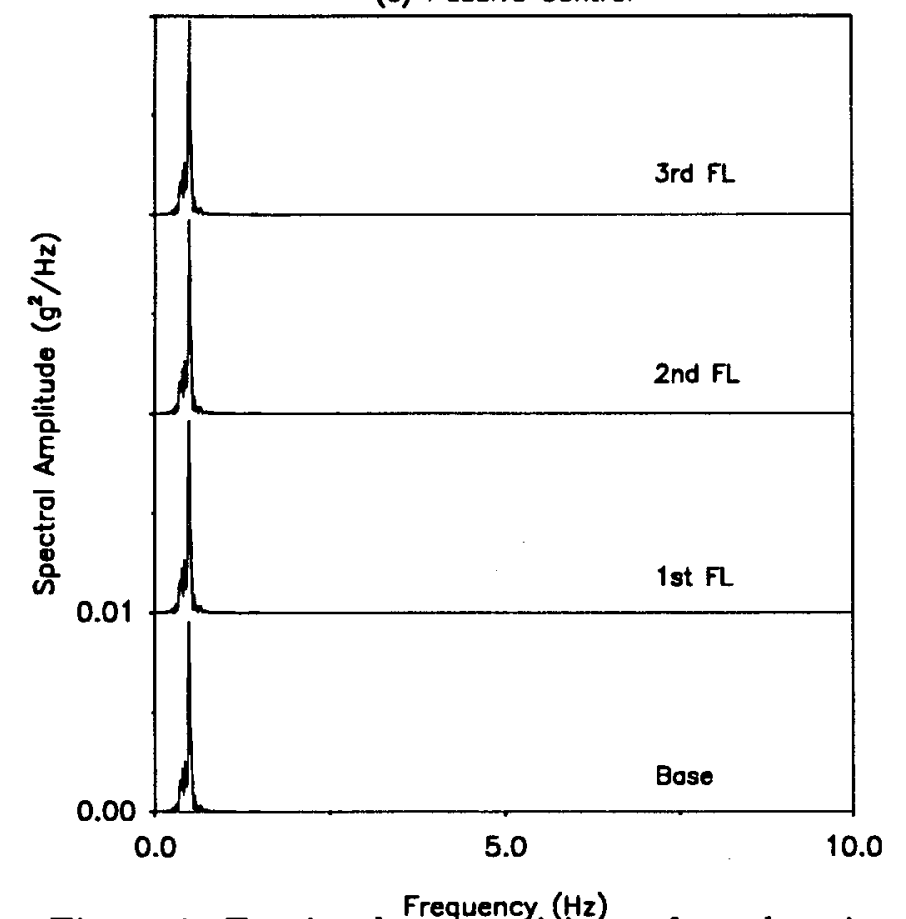

(b) Active Control

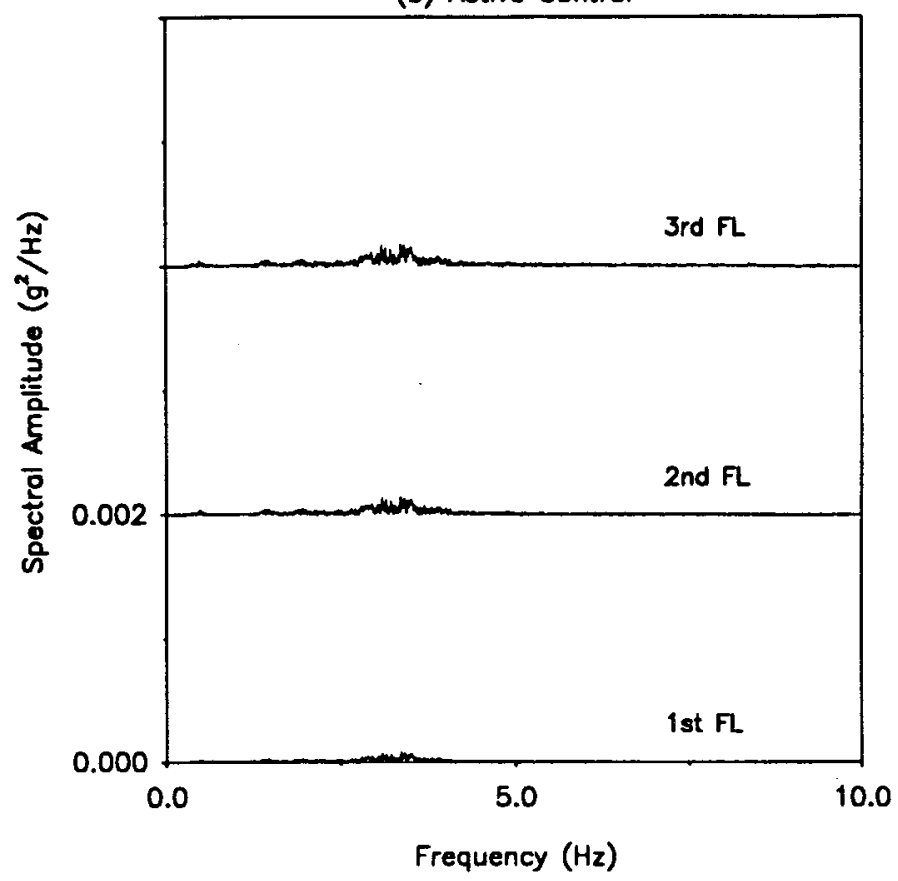

(d) Hybrid Control

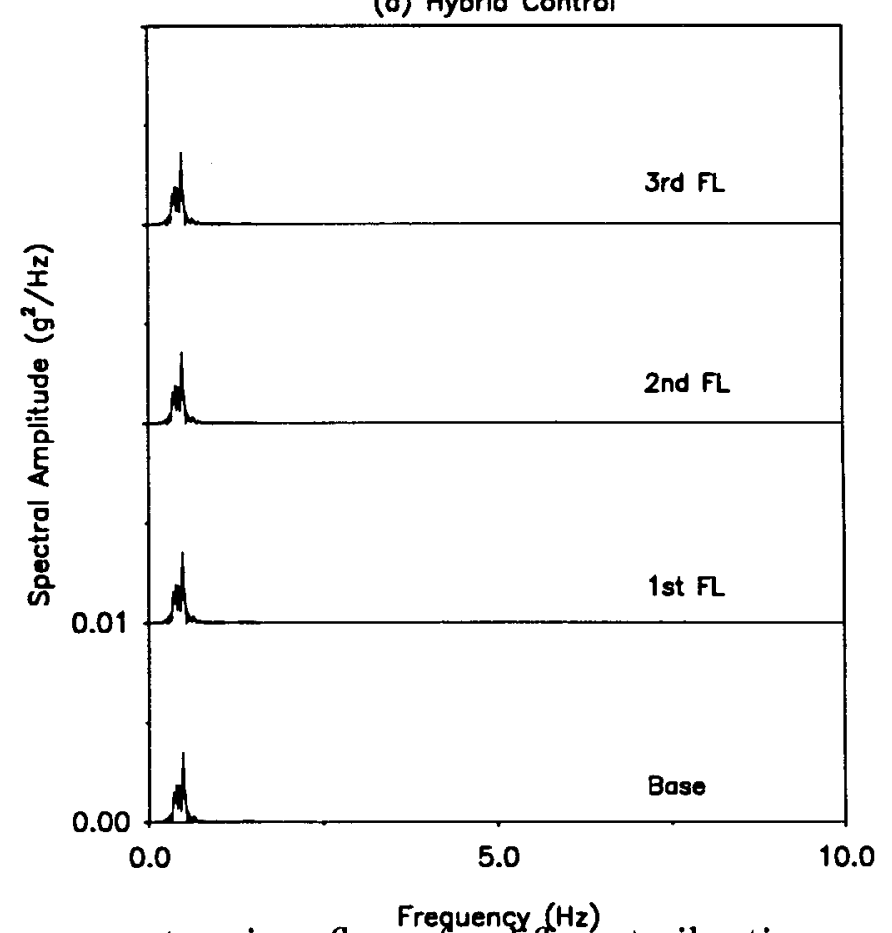

Figure 9: Fourier decompositions of acceleration responses at various floors for different vibration control systems for Mexico City 1985 earthquake. 


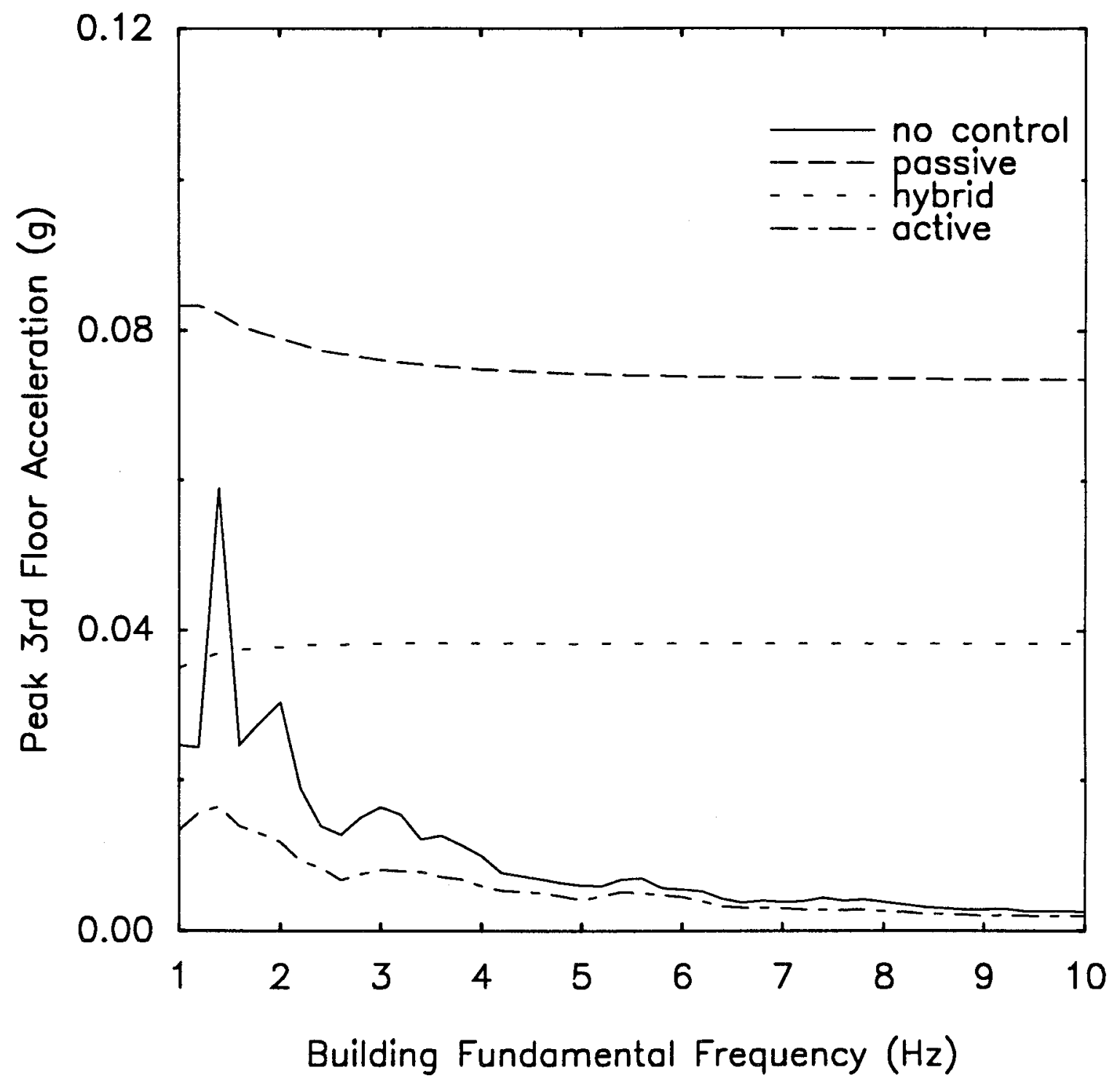

Figure 10: Peak 3rd floor acceleration responses for various vibration controllers for Mexico City 1985 earthquake. 


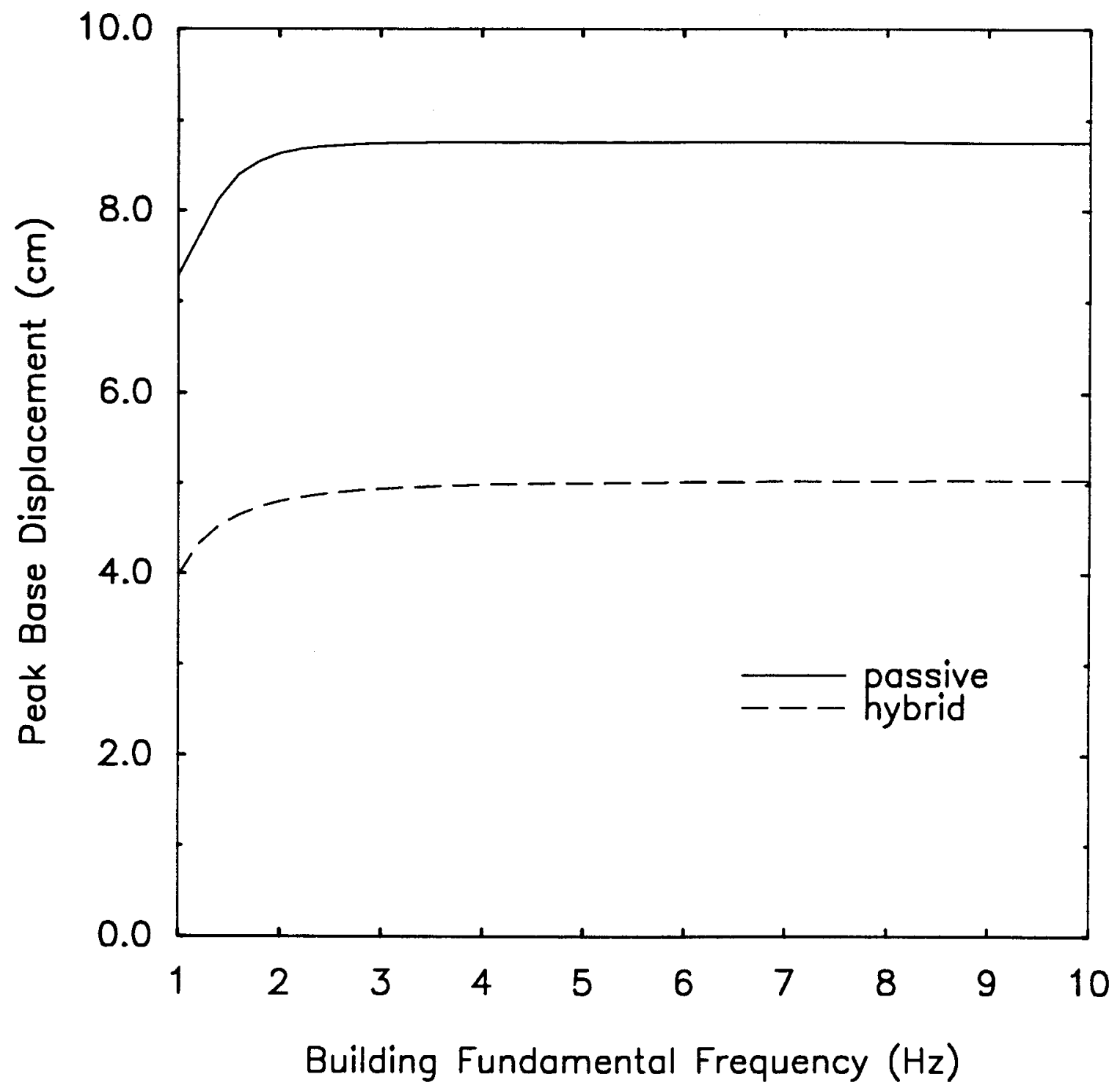

Figure 11: Peak base displacement responses for the LRB and hybrid systems for Mexico City 1985 earthquake. 
Public reporting burden for this collection of information is estimated to average 1 hour per response, including the time for reviewing instructions, searching existing data sources, gathering and maintaining the data needed, and completing and reviewing the collection of information. Send comments regarding this burden estimate or any other aspect of this collection of information, including suggestions for reducing this burden, to Washington Headquarters Services, Directorate for Information Operations and Reports, 1215 Jefferson Davis Highway, Suite 1204, Arlington, VA 22202-4302, and to the Office of Management and Budget, Paperwork Reduction Project (0704-0188), Washington, DC 20503.

\begin{tabular}{|l|l|l|}
\hline 1. AGENCY USE ONLY (Leave blank) & $\begin{array}{l}\text { 2. REPORT DATE } \\
\text { January 1995 }\end{array}$ & $\begin{array}{l}\text { 3. REPORT TYPE AND DATES COVERED } \\
\text { Technical Memorandum }\end{array}$ \\
\hline 4. TILE AND SUBTITLE & 5. FUNDING NUMBEAS \\
\hline
\end{tabular}

Integrated Passive/Active Vibration Absorber for Multi-Story Buildings $\quad$ 233-01-01-03

\section{AUTHOR(S)}

Gina J. Lee-Glauser, Goodarz Ahmadi, and Lucas G. Horta

7. PERForming ORGANIZATION NAME(S) AND ADDRESS(ES)

NASA Langley Research Center

Hampton, VA 23681-0001

8. PERFORMING ORGANIZATION REPORT NUMBER

\section{SUPPLEMENTARY NOTES}

Lee-Glauser; National Research Council Research Associate; Ahmadi, Clarkson University, Potsdam, NY;

Horta, Langley Research Center. Presented at the 36th Structures, Structural Dynamics Conference on April 10-13, 1995, New Orleans, Louisiana
12a. DISTRIBUTION/AVAILABILITY STATEMENT
12b. DISTRIBUTION CODE
Unclassified - Unlimited
Subject Category 39
Availability: NASA CASI, (301) 621-0390

\section{ABSTRACT (Maximum 200 words)}

Passive isolator, active vibration absorber, and an integrated passive/active (hybrid) control are studied for their effectiveness in reducing structural vibration under seismic excitations. For the passive isolator, a laminated rubber bearing base isolator which has been studied and used extensively by researchers and seismic designers is considered. An active vibration absorber concept, which can provide guaranteed closed-loop stability with minimum knowledge of the controlled system, is used to reduce the passive isolator displacement and to suppress the top floor vibration. A three-story building model is used for the numerical simulation. The performance of an active vibration absorber and a hybrid vibration controller in reducing peak structural responses is compared with the passively isolated structural response and with absence of vibration control systems under the NOOW component of El Centro 1940 and N9OW component of the Mexico City earthquake excitation records. The results show that the integrated passsive/active vibration control system is most effective in suppressing the peak structural acceleration for the El Centro1940 earthquake when compared with the passive or active vibration absorber alone. The active vibration absorber, however, is the only system that suppresses the peak acceleration of the structure for the Mexico City 1985 earthquake.

$\begin{aligned} & \text { 14. SUBJECT TERMS } \\
& \text { Vibration, Suppression, Passive, Active, and Hybrid Controllers Earthquake } \\
& \text { Protection }\end{aligned}$
\begin{tabular}{l|l|l|} 
17. SECURITY CLASSIFICATION \\
OF REPORT \\
Unclassified & $\begin{array}{c}\text { 18. SECURITY CLASSIFICATION } \\
\text { OF THIS PAGE } \\
\text { Unclassified }\end{array}$ & $\begin{array}{l}\text { 19. SECURITY CLASSIFICATION } \\
\text { OF ABSTRACT }\end{array}$ \\
\hline
\end{tabular}

15. NUMBER OF PAGES

21

16. PAICE CODE $\mathrm{A03}$

20. LIMITATION OF ABSTRACT 

